\title{
Sustained release of rhBMP-2 from microporous tricalciumphosphate using hydrogels as a carrier
}

Steffen Kissling ${ }^{*}$, Michael Seidenstuecker, Ingo H. Pilz, Norbert P. Suedkamp, Hermann O. Mayr and Anke Bernstein

\begin{abstract}
Background: Tissue engineering and bone substitutes are subjects of intensive ongoing research. If the healing of bone fractures is delayed, osteoinductive materials that induce mesenchymal stem cells (MSCs) to form bone are necessary. The use of Bone Morphogenetic Protein - 2 is a common means to enhance effectiveness and accelerate the healing process. A delivery system that maintains and releases BMP biological activity in controlled fashion at the surgical site while preventing systemic diffusion (and thereby the risk of undesirable effects by controlling the amount of protein implanted) is essential.

In this study, we aimed to test a cylindrical TCP-scaffold (porosity 40\%, mean pore size $5 \mu \mathrm{m}$, high interconnectivity) in comparison to BMP-2. Recombinant human BMP-2 was dissolved in different hydrogels as a carrier, namely gelatin and alginate cross-linked with $\mathrm{CaCl}_{2}$-solution, or a solution of $\mathrm{GDL}$ and $\mathrm{CaCO}_{3}$. FITC-labeled Protein A was used as a model substance for rhBMP-2 in the pre-trials. For loading, the samples were put in a flow chamber and sealed with silicone rings. Using a directional vacuum, the samples were loaded with the alginate-BMP-2-mixture and the loading success monitored by observing changes in a fluorescent dye (FITC labeled Protein A) under a fluorescence microscope. A fluorescence reader and ELISA were employed to measure the release. Efficacy was determined in cell culture experiments (MG63 cells) via Live-Dead-Assay, FACS, WST-1-Assay, pNPP alkaline phosphatase assay and confocal microscopy. For statistical analysis, we calculated the mean and standard deviation and carried out an analysis of variance.
\end{abstract}

Results: Directional vacuum makes it possible to load nearly $100 \%$ of the interconnected micropores with alginate mixed with rhBMP-2. Using alginate hardened with $\mathrm{CaCl}_{2}$ as a carrier, BMP-2's release can be decelerated significantly longer than with other hydrogels - eg, for over 28 days. The effects on osteoblast-like cells were an increase of the growth rate and expression of alkaline phosphatase while triggering no toxic effect.

Conclusion: The rhBMP-2-loaded microporous TCP scaffolds possess proliferative and osteoinductive potential. Alginate helps to lower the local growth factor dose below the cytotoxic limit, and allows the release period to be lengthened by at least 28 days.

Keywords: $\beta$-Tricalciumphosphate, Porous ceramics, Biomaterials, Alginate, Delayed drug release, Bone Morphogenetic Protein - 2 (BMP-2)

\footnotetext{
* Correspondence: steffen.kissling@t-online.de

Center for Surgery, Department of Orthopedics and Trauma Surgery, Medical

Center - University of Freiburg, Hugstetter Str.55, D-79106 Freiburg, Germany
} 


\section{Background}

The healing of bone fractures, especially critical size defects, poses a great challenge in medicine. Autologous bone grafts are routinely used, but they have drawbacks such as limited quantity and accessibility [1] and donor site morbidity. Alternative methods such as allografts, xenografts, and synthetic materials [2] were thus developed to repair bone. For human application, they must be non-toxic, non-carcinogenic, non-allergenic and noninflammatory, as well as biocompatible and biofunctional. Many scaffolds made of synthetic materials have evolved from a variety of materials like metal, polymers, and ceramics.

Ceramics are defined as being inorganic, non-metallic materials generally characterized by extreme hardness, brittleness, low electrical and thermal conductivity, great compressive strength and high chemical resistance, the latter being demonstrated by their resistance to body fluids. Epple classifies ceramic biomaterials in two categories: hard bio-inert ceramics such as zirconia or alumina, and biodegradable ceramics [3]. The latter consist of mostly calcium phosphates, which are used in bone regeneration because of their similarity to inorganic bone components such as hydroxyapatite (HA). Many calcium phosphates are used in tissue engineering. Special attention should be paid to the $\beta$ Tricalciumphosphate $(\beta$-TCP) below. $\beta$-TCP has a slightly different composition and thus another calcium/ phosphate ratio (HA 1.67; $\beta$-TCP 1.5) [4], resulting in more than twice HA's solubility in water and better degradability than HA. In medicine, $\beta$-TCP is used alone or mixed with HA (biphasic calcium phosphate) as a bone substitute material [3]. For reasons of stability, the ceramic should degrade while the new bone is forming. $\beta$-TCP has proven to be a suitable material regarding its biodegradability and mechanical stability [5].

From a structural perspective, macroporous (100$1000 \mu \mathrm{m})$ scaffolds allow cell migration and boost angiogenesis [6] and resorption from the inner surface of the pores, while the microporosity within the scaffolds exerts a positive influence on bone integration in calcium phosphate scaffolds while resorption is taking place from the outer surface. There is evidence that bone density and its mass increase thereby, and that the scaffold's osteointegration improves [7]. Combined macro- and microporous materials have recently demonstrated good ingrowth [8].

Since TCP is brittle and its high porosity leads to weak mechanical properties, our group postulated that $>60 \%$ dense TCP materials (porosity $<40 \%$ ) could be used as scaffold for bone grafting and soft tissue fixation. We assumed that micropores $(5 \mu \mathrm{m})$ would reduce brittleness by hindering crack propagation and preventing bone formation on the joint surface, and that their high interconnectivity would facilitate the nutrient transport essential for tissue engineering.

This concept was tested with a cylindrical TCPscaffold (porosity nearly $40 \%$, mean pore size $5 \mu \mathrm{m}$, high interconnectivity, axial failure load $7200 \mathrm{~N} / \mathrm{cm}^{2}$ ) in vitro and vivo. The experiments included their use as fixation for ligamentoplasties, as bone substitution [9], and as a treatment for osteochondral defects in sheep [10,11].

The implants displayed high mechanical stability (equivalent to healthy bone) [12]. The TCP resorption rate was $31 \%$, and $39 \%$ of the resorbed TCP had been replaced by mineralized bone 24 weeks after implantation. Resorption took place almost exclusively on the surface, as expected [9]. This TCP scaffold seeded with chondrocytes is also suitable for treating osteochondral defects [11].

The repair of non-critically-sized bone defects can be achieved via osteoconductive TCP scaffolds. To repair critically-sized bone defects, osteoinductive materials inducing mesenchymal stem cells (MSCs) to form bone are necessary. The use of growth factors is a common means of enhancing effectiveness and accelerating the healing process: BMP-2 is one that triggers increased bone formation [13, 14]. What is essential is a delivery system that maintains and releases BMP biological activity in controlled fashion at the surgical site while preventing systemic diffusion (and thereby the risk of undesirable effects by controlling the amount of protein implanted). The combination of microporous calcium phosphate scaffolds and BMP-2 can accelerate healing up to 4-fold [15]. In view of these encouraging results, we aimed to test this scaffold's function with Bone Morphogenetic Protein - 2 (BMP-2) in this study.

Two products using BMP-2 are commercially available and have been approved (InductOS ${ }^{\bullet}$, Pfizer; InFUSE ${ }^{\oplus}$, Medtronic) [16]. Both use collagen sponges and very high doses of BMP-2 (12 mg) without a system for retarded release. Clinically speaking, large doses of BMP-2 combined with a collagen matrix have triggered many side effects such as swelling [17], hematomas, and ossification at unintentional sites [18], and even a higher risk of cancer [19]. High in-vitro doses of BMP-2 have toxic effects on osteoblasts [20]. Another challenge when using BMP-2 for bone repair is its very short half-life lasting about $7 \mathrm{~min}$ [21]. We therefore need a delivery system that can prevent the growth factor from degrading prematurely and enable the local dose to be lowered while guaranteeing long-term delivery. Such a retarded therapeutic application should minimize complications.

The delivery can be retarded by different methods. You can bind substances adhesively or covalently to the bone substitute [22], load micro- and nanoparticles with agents [23], or use polymers like hydrogels or polylactides as a carrier [24]. 
The goal of this research was to achieve a pre-defined release of BMP-2 lasting several weeks by coupling the growth factor to a hydrogel and thus improve the mechanically-stable scaffold for bone replacement with enhanced osteoinductive properties.

\section{Methods}

The ceramic we chose to examine is $\beta$-TCP having a total porosity of $<40 \%$, while the interconnected micropores have an average pore diameter of $5 \mu \mathrm{m}$. This was used as cylindrically-shaped dowels $5 \mathrm{~mm}$ long and $7 \mathrm{~mm}$ in diameter, as described in previous studies [25].

\section{Production and characterization of the B-TCP dowels}

To manufacture the $B$-TCP dowels, a paste containing $80 \mathrm{~g}$ of $\alpha$-tricalcium phosphate $\left(\alpha\right.$-TCP; $\left.\mathrm{Ca}_{3}\left(\mathrm{PO}_{4}\right)_{2}\right)$ and $20 \mathrm{~g}$ of tricalcium phosphate (Merck, Switzerland) was mixed for 2.5 min with $60.0 \pm 0.2 \mathrm{~g}$ of a solution containing $0.2 \mathrm{M} \mathrm{Na} \mathrm{NPO}_{4}$ and $+1 \%$ polyacrylic acid (Fluka, Switzerland). During the hardening process (45 $\mathrm{min}$ ), the paste was poured into plastic syringes whose tip had been cut off $(\varnothing=23 \mathrm{~mm})$ and then covered with $10 \mathrm{ml}$ of phosphate buffer saline $\mathrm{pH} 7.4$ and incubated for 3 days at $60^{\circ} \mathrm{C}$. After drying, the ceramics were sintered at $1250{ }^{\circ} \mathrm{C}$ for $4 \mathrm{~h}$, while heating and cooling took place at $1{ }^{\circ} \mathrm{C} / \mathrm{min}$. The cylinders were then machined to obtain plugs of $25 \mathrm{~mm}$ long and $7 \mathrm{~mm}$ in diameter and calcined at $900{ }^{\circ} \mathrm{C}$ to burn off all organic residues. Afterwards the plugs were cut into $5 \mathrm{~mm}$ long dowels and then washed in ethanol and distilled water in an ultrasonic bath to remove residual wear particles and sterilized by heat $\left(200{ }^{\circ} \mathrm{C}, 4 \mathrm{~h}\right)$ for cell culture trials. This fabrication process has been described in greater detail in previous studies $[5,12,25]$.

The fabricated $B$-TCP plugs were phase pure as assessed by X-ray diffraction (XRD) and tested on a Bruker axs D8 Advance X-ray diffractometer (Billerica, USA).

The ceramics were microporous (mean pore size 5.05 $\pm 1.61 \mu \mathrm{m}$ ) with interconnecting pores and a total porosity of $35.2 \pm 1.5 \%$. Porosity was assessed on a POROTEC Pascal 440 (Hofheim, Germany) mercury porosimeter.

\section{FITC-Protein $A$ as a model substance}

In the pretrial, Protein A (441 AS, $42 \mathrm{kDa}$ ) was used as a model substance for rhBMP-2 (396 AS, homodimer $30 \mathrm{kDa}$ ) because of its similar hydrodynamic volume and chemical structure. Apart from the financial aspects, Protein A can be FITC-labeled (Invitrogen, California), making measuring easy and precise.

\section{Hydrogels as carrier systems}

We chose to evaluate three hydrogels: alginate $5 \% \mathrm{w} / \mathrm{v}$ cross-linked with $\mathrm{CaCl}_{2}$ solution as an external $\mathrm{Ca}^{2+}$ source; self-hardening alginate [26] $5 \% \mathrm{w} / \mathrm{v}$ cross-linked with $34 \mathrm{mM}$ glucono- $\delta$-lactone (GDL), obtained from Sigma-Aldrich (Missouri, USA), and $34 \mathrm{mM} \mathrm{CaCO}$ (Fluka, Switzerland); gelatin with a Bloom value of 300 (Gelita, Germany).

For the trials with rhBMP-2, alginate cross-linked with $\mathrm{CaCl}_{2}$ was chosen as a carrier because of its ideal release characteristics. The sodium alginate was produced as $5 \% \mathrm{w} / \mathrm{v}$ alginate sol made with distilled water. To increase rhBMP-2 solubility, we added hydrochloric acid to $\mathrm{pH} 4$. To ensure the best possible distribution in the sol, rhBMP-2 (Pfizer) [50 $\mu \mathrm{g} / \mathrm{ml}]$ or FITC-labeled Protein A [50 $\mu \mathrm{g} / \mathrm{ml}]$ were added to the distilled water immediately as production started. To prevent premature fading, the brine was homogenized in total darkness by wrapping the beaker glass in aluminum foil. To load the ceramics, we designed and manufactured a flow chamber from stainless steel. A directional vacuum was used for loading. There is a low vacuum of $40 \mathrm{mbar}$ on one side of the flow chamber, while the pressure is atmospheric on the other side above the reservoir tank. In the flow chamber, the ceramic dowels are inserted in a silicone seal (FDA approved, LabMarket, Germany) that ensures that loading occurs only via the end surfaces of the microporous ceramic cylinders. This loading procedure guarantees a $100 \%$ load of the micropores [27]. After loading, the dowels were incubated in $30 \mathrm{mM}$ $\mathrm{CaCl}_{2}$ (Carl Roth, Germany) for $5 \mathrm{~h}$ at room temperature (ca. $20^{\circ} \mathrm{C}$ ) to harden the gel.

\section{Release kinetics}

To simulate the physiological environment, the loaded dowels (FITC-Prot.A $n=7$; BMP-2 $n=6$ ) were incubated in phosphate buffer saline (gibco life technologies, California) at $37{ }^{\circ} \mathrm{C}$ and $5 \% \mathrm{CO}_{2}$. The phosphate buffer saline was completely replaced at each measuring point $(1$, $2,3,6,9,14,21,28$ days).

The release of FITC-Protein A was measured via fluorescence spectroscopy (Tecan infinite 200) at $525 \mathrm{~nm}$ wavelength, while absorption was $495 \mathrm{~nm}$ wavelength. A six-point calibration curve was used (corr. $\mathrm{R}^{2} 0,977$ ). The release of rhBMP-2 was measured by ELISA (R\&DSystems, Minnesota, USA) according to the protocol (seven-point Standard, corr. $\mathrm{R}^{2}$ 0,988).

\section{Osteoinductive capacity of released BMP-2}

The efficacy of the released rhBMP-2 was calculated by its effect on osteoblast-like cells (MG63, ATCC CRL1427). Those cells were grown in DMEM F12 Medium (Lonza, Switzerland) and incubated in $5 \% \mathrm{CO}_{2}$ at $37{ }^{\circ} \mathrm{C}$.

\section{Live-dead assay}

First, the toxic and apoptotic potential of the amount of rhBMP-2 that had been released was assessed by fluorescence-activated cell sorting (FACS) with propidium 
iodide( $1 \mathrm{mg} / \mathrm{ml}$, Invitrogen, California). FACS is a specialized type of flow cytometry. It enables the analysis of cells that pass an electric voltage or a light beam at high speed. Depending on the cells' shape, structure, and/or staining, different effects are produced from which the cells' properties can be derived. Propidium iodide is discharged from vital cells only. Propidium iodide-positive cells represent dead or severely damaged cells.

$1 \times 10^{4}$ MG63 cells were seeded per well on 24-wellplates and treated with $1 \mu \mathrm{g}$ rhBMP-2 per $24 \mathrm{~h}$ for three days, which was the maximum daily release. Afterwards the cells were trypsinized, washed, and treated with $2 \mu \mathrm{l}$ propidium iodide solution. The populations were detected by FACSCalibur flow cytometry (Becton Dickinson, New Jersey, USA). MG63-cells without rhBMP-2treatment served as a control. 1000 events were counted per group.

To confirm our findings (3.3), we examined the cells on the surface of the scaffold using a live/dead Cell Staining Kit (Promokine, Germany). In this trial, $1 \times 10^{4}$ MG63 cells were seeded on top of the scaffold and dyed with AM/EthD-III -dyeing after 24, 48 and $96 \mathrm{~h}$.

Fluorescein dye has an excitation maximum at $495 \mathrm{~nm}$ and an emission maximum at $515 \mathrm{~nm}$ (green). Ethidium bromide is not absorbed by intact cell membranes, has an excitation maximum at $530 \mathrm{~nm}$ and an emission maximum at $635 \mathrm{~nm}$ (red). Vital cells reveal green, nonvital cells red fluorescence in fluorescence microscopy with blue light. The analysis was done manually.

\section{Proliferation assay}

Proliferation was measured with WST-1 Assay (Roche, Switzerland). For each measuring point at $24 \mathrm{~h}, 48 \mathrm{~h}$, $96 \mathrm{~h} ß$-TCP dowels $(n=2)$ were loaded with $5 \% \mathrm{w} / \mathrm{v}$ alginate including $50 \mathrm{ng} / \mathrm{ml} \mathrm{rhBMP}-2$ and hardened with $30 \mathrm{mM} \mathrm{CaCl}$ as described above. The total amount of rhBMP-2 was $3.85 \mu \mathrm{g}$ per plug. Dowels loaded only with $5 \% \mathrm{w} / \mathrm{v}$ alginate served as control. $1 \times 10^{\wedge} 4 \mathrm{MG} 63-$ cells were seeded into 24-well-plates and incubated in $1 \mathrm{ml}$ DMEM F12 medium. After a settle-time of $8 \mathrm{~h}$, the loaded dowels were added to the medium and cells in cell culture inserts (BDFalcon, New Jersey, USA) with a pore size of $1 \mu \mathrm{m}$. At each measuring point the inserts and dowels were removed, $100 \mu \mathrm{l}$ of WST-1-reagent was added and mixed well. After $2 \mathrm{~h}$ of incubation, absorption was measured at $450 \mathrm{~nm}$ wavelength (Tecan infinite 200, Tecan Group, Switzerland). Each sample was measured 4 times. The tetrazolium salts of the WST-1-reagent are cleaved to formazan by cellular enzymes. An increase in the number of viable cells raises the overall activity of mitochondrial dehydrogenases and thereby an increase in the total amount of formazan. This can be detected with a Reader at a wavelength between $420-480 \mathrm{~nm}$.

\section{Alkaline phosphatase assay and confocal microscopy}

Osteoblastic differentiation was meted with SensoLyte ${ }^{\circ}$ pNPP Alkaline Phosphatase Assay Kit (Anaspec EGT Group, California, USA). For each measuring point at $3 \mathrm{~d}, 7 \mathrm{~d}$, and $14 \mathrm{~d}, \mathrm{~B}$-TCP dowels $(n=3)$ were loaded with $5 \% \mathrm{w} / \mathrm{v}$ alginate including $50 \mathrm{ng} / \mathrm{ml} \mathrm{rhBMP}-2$ and hardened with $30 \mathrm{mM} \mathrm{CaCl}_{2}$. The total amount of rhBMP-2 was $3.85 \mu \mathrm{g}$ per dowel. Ceramics loaded only with $5 \% \mathrm{w} / \mathrm{v}$ alginate served as a control. $1 \times 10^{4}$ MG63-cells were seeded per well into 24-well-plates and incubated in $1 \mathrm{ml}$ DMEM F12 Medium (Lonza, Switzerland). After $8 \mathrm{~h}$ of settle-time, the loaded dowels were added to the medium in cell culture inserts (BDFalcon, New Jersey, USA) as described above. At the measuring points the inserts and dowels were removed, the cells lysed with Triton X-100, and the supernatant collected for the assay. A seven-point calibration curve (corr. $\mathrm{R}^{2} 0,998$ ) was set and each sample measured twice. The assay detects only biologically-active alkaline phosphatase. pnitrophenyl phosphate is dephosphorylized by AP while the substrate turns yellow and can be detected at $405 \mathrm{~nm}$ wavelength with a Reader.

Another way to demonstrate AP increase is via confocal microscopy (Leica TCS SP2 AOBS spectral confocal microscope), where light can be separated from the object's different levels. The use of fluorescent dyes and the observation laser's different wavelengths enable assessment of the spatial distribution of labeled compounds. In this case, $1 \times 10^{4}$ MG63-cells were seeded on Thermanox $^{\circ}$ (Thermo Scientific, Massachusetts, USA) membranes in 24-well-plates and incubated in $1 \mathrm{ml}$ DMEM F12 medium and treated with rhBMP-2, as released from the scaffolds for 5 days. After the treatment, the cells were washed with phosphate buffer saline, fixed with methanol, protein-blocked and incubated with primary antibody (rabbit anti-alkaline phosphatase 1:100, Abcam, England) over night. The next day the membranes were washed again and incubated with secondary antibody (Donkey anti-Rabbit IgG, Alexa Fluor 555; life technologies, California) for $1 \mathrm{~h}$. Cell nuclei were dyed with DAPI (life-technologies, California).

\section{Statistics}

Data is expressed as mean values \pm standard deviation of the mean and analyzed by one-way analysis of variance (ANOVA). The level of statistical significance was set as $p<0.05$. For statistical calculations Origin 9.1 Professional SR1 (OriginLab) was used.

\section{Results}

\section{The most retardant hydrogel}

FITC -Protein A release was very rapid from the gelatin and self-hardening alginate: $80.9 \%$ of the gelatin and $76.1 \%$ from the self-hardening alginate had been 
released after $24 \mathrm{~h}$. After 9 days, the concentration was already under the detection limit.

The release of alginate with an external $\mathrm{Ca}^{2+}$ source measured only $35.6 \%$ of the total after $24 \mathrm{~h}$. After the release experiment, the scaffolds were broken and scrutinized under a fluorescence microscope. There was still some FITC Protein A left in the scaffolds loaded with alginate hardened with an external $\mathrm{Ca}^{2+}$ source, while there was nothing in the dowels loaded with selfhardening alginate and gelatin.

Thus the initial burst phase was significantly reduced while the second release phase was prolonged for over 28 days (cf. Fig. 1). After 28 days of release, there is still some FITC Protein A incorporated in micropores of the scaffold loaded with alginate hardened with an external $\mathrm{Ca}^{2+}$ source. In contrast to the self-hardening alginate, the incorporated FITC Protein A can be visualized by fluorescence microscopy (cf. Fig. 2a and b).

\section{Retarded release of BMP-2 from an alginate-loaded B-TCP dowel}

Release of rhBMP-2 from the ceramics was very similar. Only the release on day 1 was lower, which can be ascribed to rhBMP-2 or FITC-Prot. A missing in the hardeningsolution $\left(\mathrm{CaCl}_{2}\right)$ and diffusion during the 5 -h process.

Maximum release was $959 \pm 222 \mathrm{ng} / \mathrm{ml}$ rhBMP-2 on the second day. After 14, 21 and 28 days, we still observed a release of $268 \pm 59 \mathrm{ng} / \mathrm{ml}, 111 \pm 20 \mathrm{ng} / \mathrm{ml}$ and $56 \pm 16 \mathrm{ng} / \mathrm{ml}$.

There is thus an initial burst phase followed by lengthier release phase lasting several weeks (cf. Fig. 3, raw data cf. Additional File 1).

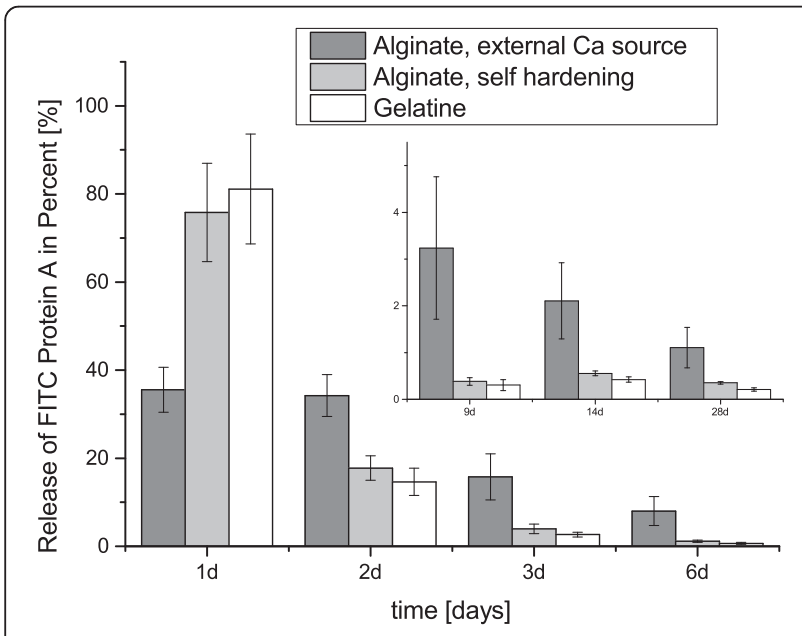

Fig. 1 Comparison of the release kinetics of three different hydrogels regarding FITC Protein A measured by fluorescence reader in a 28-day-trial (incubation at $37^{\circ} \mathrm{C}$, Phosphate buffer saline changed completely at each measuring point): The alginate with external Ca2+ source reveals a significantly reduced burst release, while the second release phase is prolonged
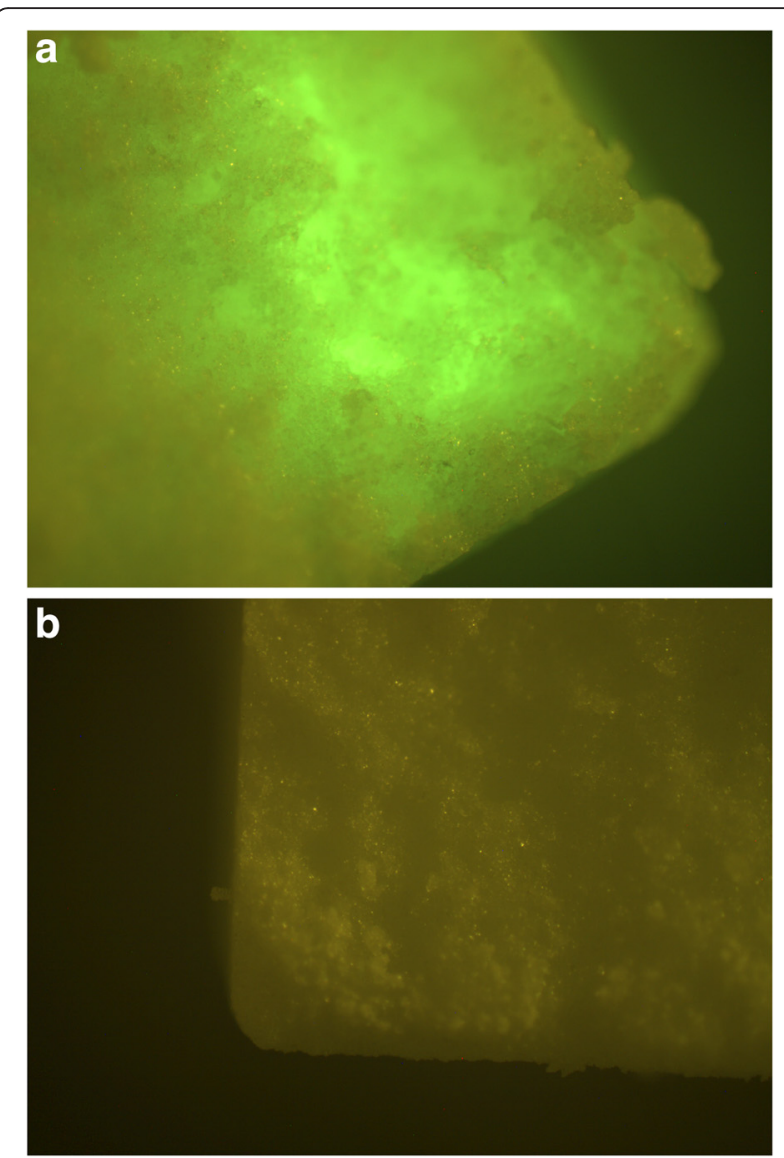

Fig. 2 Fluorescence microscopy (Olympus BX-51, blue light filter) of alginate and FITC-Protein A-loaded dowels after 28 days' incubation at $37^{\circ} \mathrm{C}$, Phosphate buffer saline changed completely at each measuring point; a (left): Remaining FITC Protein A in dowel (Alginate with external Ca2+ source) b (right): No FITC Protein A left in dowel loaded with self-hardening alginate

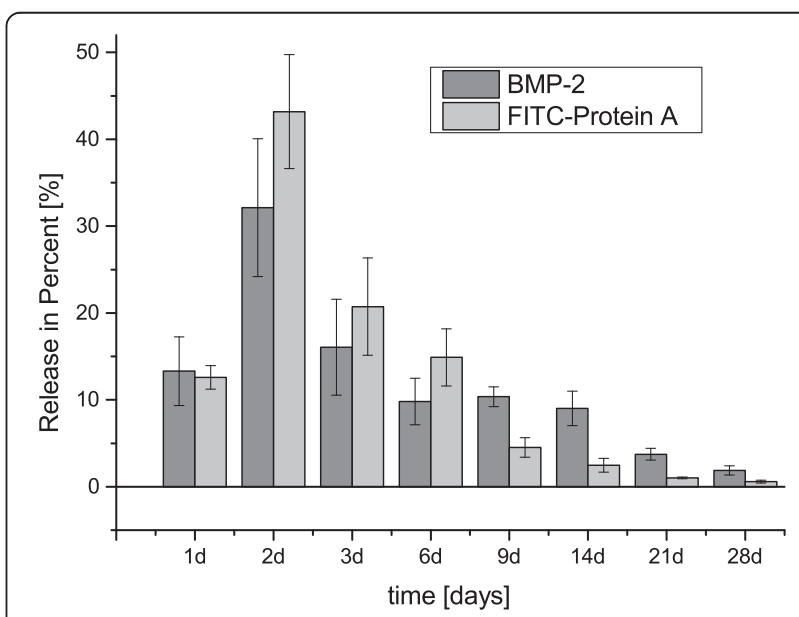

Fig. 3 Considerably retarded release of BMP-2 from the externallyhardened alginate-loaded B-TCP dowel in a 28-day-trial; BMP-2 load $3.85 \mu \mathrm{g} / \mathrm{scaffold}$; incubation at $37^{\circ} \mathrm{C}$; Phosphate buffer saline changed completely at each measuring point 


\section{Proliferation and osteogenic potential}

The results of FACS measuring with propidium iodide revealed no significant difference between the blanc and the group treated with $1 \mu \mathrm{g} / \mathrm{ml}$ rhBMP-2 (Table 1 ).

Results of the live/dead assay with AM/EthD-III staining displayed no significant difference between the scaffolds with and without loading with rhBMP-2.

In the WST-1-Assay, the groups displayed significant differences in proliferation rate at a significance level of $p<0.05$. Proliferation of the MG63 cells incubated with the rhBMP-2 loaded scaffolds was significantly higher at all measured time points (cf. Fig. 4, raw data cf. Additional File 2). The increase was $+38.3 \%$ after $24 \mathrm{~h}$, rising to $+50.3 \%$ after $48 \mathrm{~h}$ and only $+35.4 \%$ when reaching the culture plateau phase after 4 days.

The pNPP alkaline phosphatase assay revealed differences between the blancs and rhBMP-2-group (cf. Fig. 5, raw data cf. Additional File 3). The concentration of active AP increased from $5.9 \pm 0.9 \mathrm{ng} / \mathrm{ml}$ to $7.9 \pm 0.3 \mathrm{ng} / \mathrm{ml}$, equaling $24.8 \%$ after 7 days. The increase after $14 \mathrm{~d}$ was from $10.1 \pm$ $1.3 \mathrm{ng} / \mathrm{ml}$ to $15.1 \pm 2.8 \mathrm{ng} / \mathrm{ml}$, or $33 \%$. These results were not significant at a significance level of $p<0.05$.

\section{Discussion}

Bone morphogenetic proteins have been investigated intensively on both experimentally and clinically in orthopedic surgery. Especially in the early stages of bone regeneration, BMP-2 recruits local sources of skeletal progenitor cells and determines their course towards the osteogenic lineage. The current therapeutic application of BMP-2 for bone repair is nevertheless associated with unacceptable side effects and very high doses. The ideal carrier matrix should provide localized, retarded, and active BMP-2 delivery. Moreover, it should fulfill cell, attachment, proliferation, and differentiation requirements. We assumed that BMP-2 loaded microporous B-TCP scaffolds, prepared by mixing BMP-2 solution with alginate and by loading the porous ceramics and hardening the alginate sol to a gel, would deliver a prolonged release system complying with these requirements. With this method, it is possible to include any concentration of one or more active ingredients in the scaffold. After the alginate has been hardened with calcium chloride, the diffusion from the gel -containing micropores into the surrounding area is delayed. Significant delays are observed in the release of antibiotics and growth factors

Table 1 MG63 cells after treatment with $1 \mu \mathrm{g}$ BMP-2 per $24 \mathrm{~h}$ for 3 days display no differences in survival, measured by FACS with propidium lodide

Group alive [\%] dead [\%]

Blanc $97.6 \pm 0.42 .4 \pm 0.4$

BMP-2 $(1 \mu \mathrm{g} / \mathrm{d}) 97.8 \pm 0.22 .2 \pm 0.2$

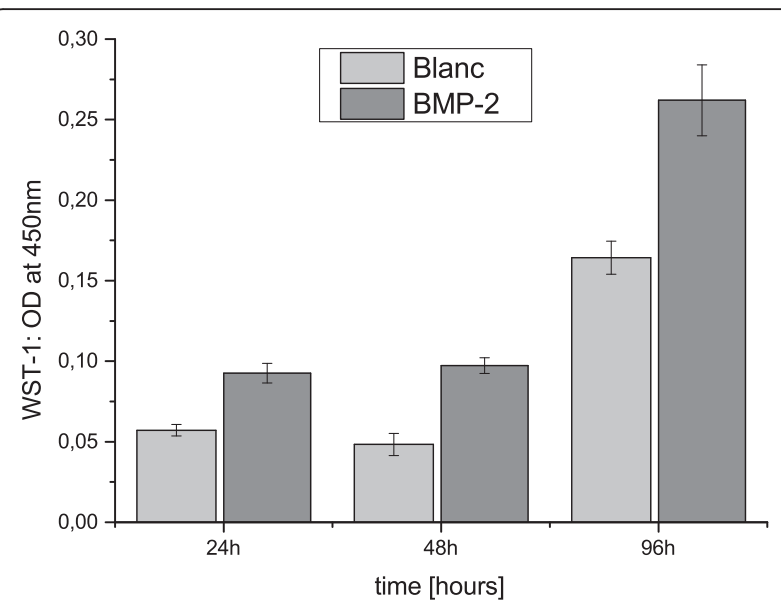

Fig. 4 Significant proliferation differences in WST-1-Assay of MG63 cells after cultivation with BMP-2 and alginate-loaded B-TCP scaffolds for $24 \mathrm{~h}, 48 \mathrm{~h}$ and $96 \mathrm{~h}$

when applying this method [24]. The amount of delay can be adjusted by altering the carrier substance's rheological properties. Alginate and calcium concentrations can therefore be modified. Alternatively, an alginate with longer molecular chains could be used. However, microporous ceramics cannot be loaded with fluids that are too viscous. The Bernstein working group has explored the limits of this loading process.

There are other means of controlling a substance's release from bone-replacement materials. Zurlinden et al. demonstrated that you can bind rhBMP-2 covalently to calcium phosphate granular materials and delay the release up to a few hundred days by using sodium acetate (half-life up to 115 days) [28]. The amount of substances released daily decreases with the prolongation of desorption. The release period is longer than with hydrogels, but the amount of substances released daily is lower [29].

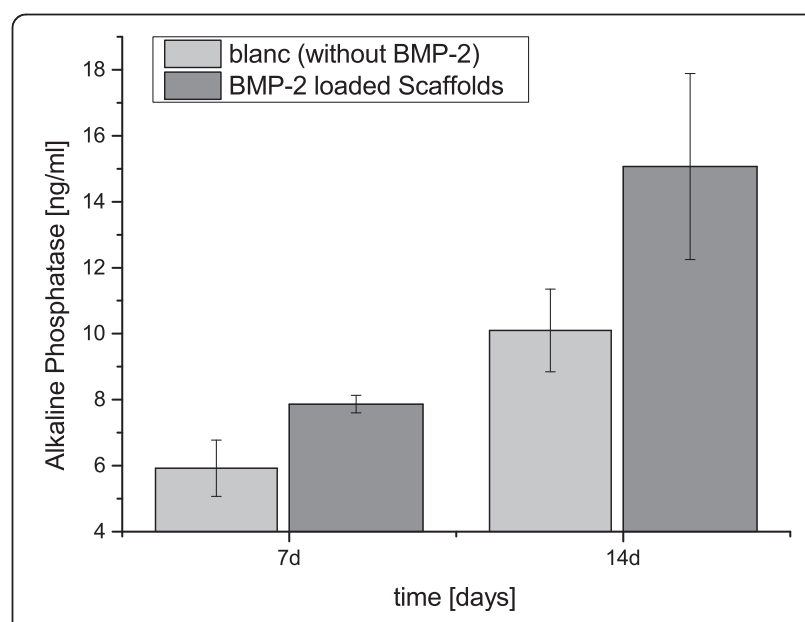

Fig. 5 Expression of alkaline phosphatase in pNPP alkaline phosphatase assay after cultivation with BMP-2 and alginate-loaded B-TCP scaffolds 
We have observed a burst release within the first $48 \mathrm{~h}$ of release $(45.4 \%)$, while $50.9 \%$ of the BMP-2 release occurs during the remaining 28 days when a hydrogel is combined with a $B$-TCP ceramic. The relatively fast release of BMP-2 may be attributed to the relatively large amount of BMP-2 adsorbed on hydrogel on the top of ceramic cylinders due to the ceramic loading process. At the last measuring point on day $28,56 \pm 16 \mathrm{ng} / \mathrm{ml}$ remained: about $2 \%$ of the BMP- 2 measured. This continuous BMP-2 release implies that abundant BMP-2 had been packed into the ceramic micropores. We noted homogeneous distribution of the hydrogel inside the entire ceramic. This amount suffices to stimulate osteoblasts' migration and differentiation. In-vitro effects of BMPs are observed at very low doses (5-20 ng/mL) [16]. Most other studies have reported that substrate loaded with BMP-2 has a significantly fast in-vitro release rate. This has also revealed an initial burst release exceeding $50 \%$, and a slow slow-release stage [30, 31].

Many studies investigating BMP-2 delivery for bone repair have applied relatively high doses ranging from tens to hundreds of micrograms [32-34] and even 6-12 milligrams [35]. This makes treatment costly while exacerbating the drawback of side effects. High doses have also displayed negative effects on different bone cells in-vitro, inducing apoptosis from a few hundred nanograms upwards [36]. Our working group's pretrials have yielded similar results.

Other recent studies have investigated the use of lower doses in the range of a few micrograms [37] achieving for example a $55 \%$ increase in bone volume compared to empty defects 6 weeks after the implantation of polymer scaffolds containing only $1 \mu \mathrm{g}$ BMP- 2 in mice [38]. Findings like these encouraged us to reduce the total BMP-2 load down to $3.85 \mu \mathrm{g}$ per scaffold, enabling us to reduce the daily release to significantly under the toxic and apoptotic threshold while ensuring a maximum release of $1 \mu \mathrm{g} /$ day using the stiffest alginate from an external $\mathrm{Ca}^{2+}$ source (in comparison to a self-hardening alginate). The combination of an alginate from an external $\mathrm{Ca}^{2+}$ source with microporous $ß-\mathrm{TCP}$ ceramic provides a promising delivery system for BMP-2. There would be enough BMP-2 in-vivo in the first 4 weeks of bone healing, with just a little left for the remainder of the degradation period (52 weeks in a sheep model [11]). The other hydrogels we investigated (self-hardening alginate and gelatin) displayed a significant burst release due to their greater physical solubility. They are therefore unsuitable in a carrier system. Apart from the fact that the release of rhBMP-2 and Protein A is very similar, it is a good and inexpensive model substance.

BMP-2's in-vivo effects on osteoblasts and bone are well known [39]. Our trial was designed to demonstrate that released rhBMP-2 remains active after being dissolved in alginate following the loading procedure and release. We hypothesized that proliferation and the expression of osteogenic markers like AP would rise, as described in other studies [40].

BMP-2 proliferation seems to have contradictory effects on different types of cells. Fromigue' et. al. postulated in 1998 that BMP-2 decreases proliferation up to $35 \%$ in human bone marrow cells representing early progenitors [41] while other groups were unable to detect significant differences in osteosarcoma cell lines representing osteoblast-like-cells [42]. Having observed no other differences between the groups, we attribute this increase in proliferation to the released BMP-2.
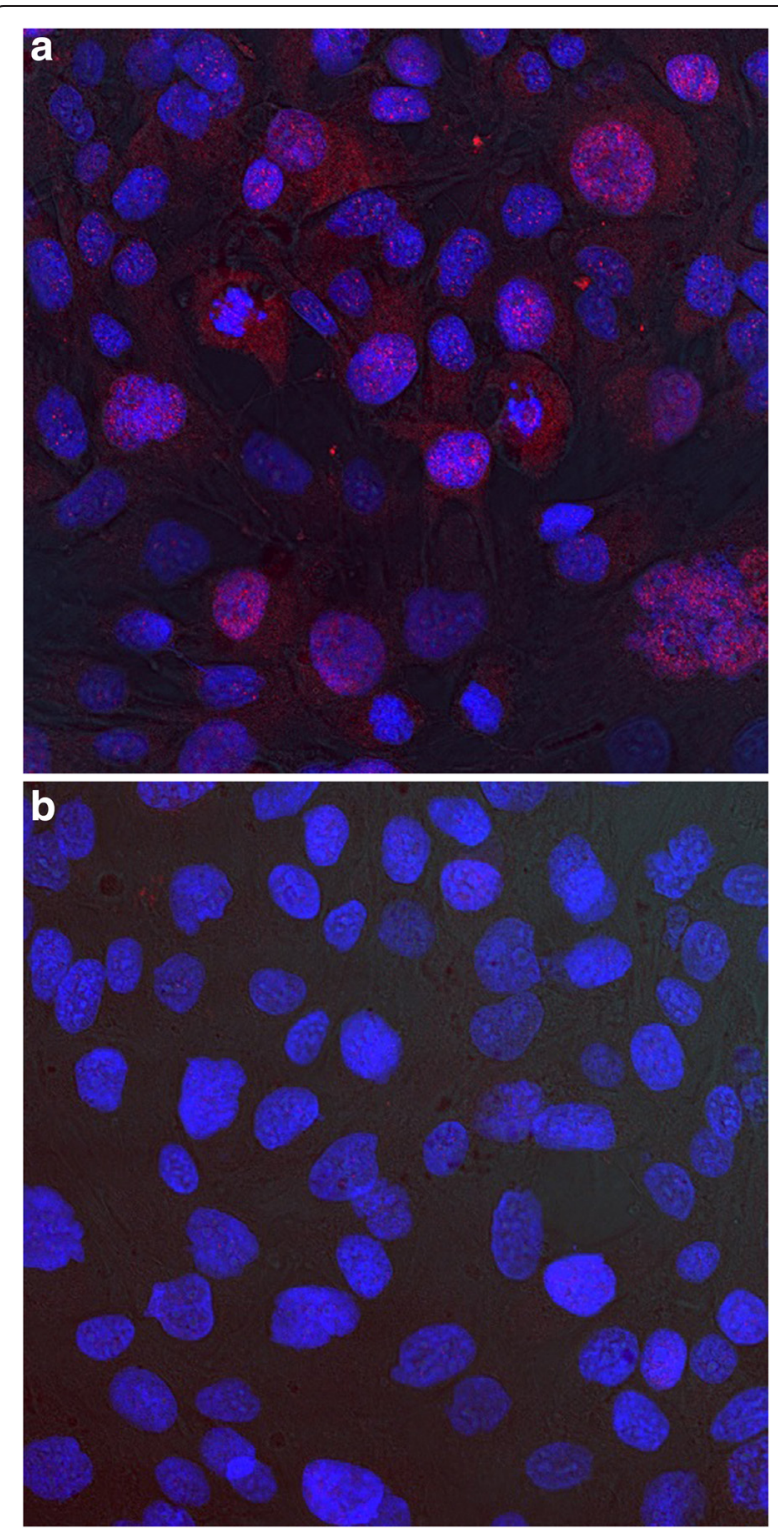

Fig. 6 A (BMP-2) and 6 B (blanc): Confocal microscopy of MG63 cells after treatment with rhBMP-2 (left) and without (right) for 5 days, differences in expression of alkaline phosphatase. Cell nuclei blue (DAPI), AP red (rabbit anti-AP-AB; donkey anti rabbit, Alexa555) 
The rhBMP-2 treated groups displayed higher AP activity than the groups lacking rhBMP-2 (cf. Fig. 6) (up to $33 \%$ in our experiments), but not to a significant degree in the alkaline phosphatase assay. Perhaps the measuring points play a role; Draenert et. al. describe the maximum difference at $24 \mathrm{~h}$ using human osteoblasts [40]. Higher case numbers could also have helped achieve more convincing findings, as other working groups have employed [43]. Furthermore, rhBMP-2 handling could be optimized. A combination with heparin may lead to further improvement because heparin is a highly sulfated glycosaminoglycan known to bind to BMP-2 and stimulate its activity by protecting it from enzymatic degradation and the antagonistic actions of noggin [44], a protein involved in the development of tissues such as nerves, muscles, and especially bones. The same working group showed that acidic $\mathrm{pH}$ and the use of glass vials can lead to improved BMP-2 stability when compared with physiological $\mathrm{pH}$ and the use of plastic vials [45].

\section{Conclusion}

It was our aim to amalgamate an osteoconductive, microporous, interconnective 3 -TCP-scaffold with rhBMP-2. This scaffold consisting of a microporous $B$-TCP ceramic and an alginate hydrogel with rhBMP-2 represents a promising delivery system for BMP-2.

We observed that BMP-2 exerts effects on osteoblastlike cells at very low doses over a lengthy period. We also believe that such scaffolds can lead to better and safer outcomes in humans.

\section{Additional files}

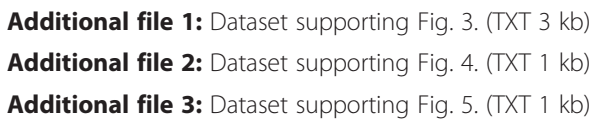

\section{Abbreviations \\ AP: alkaline phosphatase; BMP: bone morphogenetic protein; Ca: calcium; CaP: calciumphosphate; Cl: chloride; DMEM F12: Dulbeccos modified eagle medium: nutrient mixture F12; ESEM: environmental scanning electron microscope; FACS: fluorescence-activated cell sorting; FCS: fetal calf serum; FITC: fluorescein isothiocyanate; GDL: glucono delta lactone; HA: hydroxyapatite; MG-63: immortalized human osteosarcoma cell line; MSC: mesenchymal stem cell; TCP: tricalciumphosphate; w/v: weight per volume; XRD: X-ray diffraction.}

\section{Acknowledgements}

The authors thank AG Kern, Institute for Manufacturing Technologies of Ceramic Components and Composites, Stuttgart for porosimetry and XRDmeasurements.

\section{Authors' contributions}

SK performed the release experiments, the cell culture experiments, and wrote the manuscript. MS designed the flow chamber. IP performed the FACS and Confocal Microscopy. NS designed our study. HM made the microporous ceramics. AB realized the fluorescence microscopy and took care of the financing. All authors read and approved the final manuscript.

\section{Funding}

This research project is being funded by the German section of the international AO Foundation (AO). The rhBMP-2 was provided by Pfizer. The article processing charge was funded by the German Research Foundation (DFG) and the Albert Ludwigs University Freiburg in the funding programme Open Access Publishing.

\section{Availability of data and materials}

The raw datasets supporting the conclusions of this article are included within the article and its additional files as.txt-files.

\section{Competing interests}

The authors declare that they have no competing interests.

\section{Consent for publication}

Not applicable.

\section{Ethics approval and consent to participate}

Not applicable.

Received: 27 March 2015 Accepted: 12 May 2016

Published online: 20 May 2016

\section{References}

1. Greenwald AS, Boden SD, Goldberg VM, Khan Y, Laurencin CT, Rosier RN. Bone-graft substitutes: Facts, fictions, and applications. J Bone Joint Surg Am. 2001;83A:98-103.

2. Kao ST, Scott DD. A review of bone substitutes. Oral Maxillofac Surg Clin North Am. 2007;19:513-21.

3. Epple M. Biomaterialien und Biomineralisation: Eine Einführung für Naturwissenschaftler, Mediziner und Ingenieure. Vieweg + Teubner Verlag: Wiesbaden; 2003.

4. Klein CP, Driessen AA, de Groot K, van den Hooff A. Biodegradation behavior of various calcium phosphate materials in bone tissue. J Biomed Mater Res. 1983;17:769-84.

5. Bernstein A, Nöbel D, Mayr HO, Berger G, Gildenhaar R, Brandt J. Histological and histomorphometric investigations on bone integration of rapidly resorbable calcium phosphate ceramics. J Biomed Mater Res. 2008;84B:452-62.

6. Walthers CM, Nazemi AK, Patel SL, Wu BM, Dunn JCY. The effect of scaffold macroporosity on angiogenesis and cell survival in tissue-engineered smooth muscle. Biomaterials. 2014;35:5129-37.

7. Hing KA, Annaz B, Saeed S, Revell PA, Buckland T. Microporosity enhances bioactivity of synthetic bone graft substitutes. J Mater Sci Mater Med. 2005; 16:467-75.

8. Lan Levengood SK, Polak SJ, Wheeler MB, Maki AJ, Clark SG, Jamison R, Wagoner Johnson AJ. The effect of BMP-2 on micro- and macroscale osteointegration of biphasic calcium phosphate scaffolds with multiscale porosity. Acta Biomater. 2010;2009:3282-91.

9. Mayr HO, Dietrich M, Fraedrich F, Hube R, Nerlich A, von Eisenhart-Rothe R, et al. Microporous pure beta-tricalcium phosphate implants for press-fit fixation of anterior cruciate ligament grafts: strength and healing in a sheep model. Arthroscopy. 2009;25:996-1005.

10. Mayr HO, Klehm J, Schwan S, Huber R, Südkamp NP, Niemeyer $P$, et al. Microporous calcium phosphate ceramics as tissue engineering scaffolds for the repair of osteochondral defects: biomechanical results. Acta Biomater. 2013;09:4845-55.

11. Bernstein A, Niemeyer P, Salzmann G, Südkamp NP, Hube R, Klehm J, et al. Microporous calcium phosphate ceramics as tissue engineering scaffolds for the repair of osteochondral defects: histological results. Acta Biomater. 2013; 07:7490-505.

12. Mayr HO, Hube R, Bernstein A, Seibt AB, Hein W, von Eisenhart-Rothe R. Beta-tricalcium phosphate plugs for press-fit fixation in $A C L$ reconstruction-a mechanical analysis in bovine bone. Knee. 2007;14:239-44.

13. Urist MR. Bone formation by autoinduction. Science. 1965;150:893-9.

14. Groeneveld EH, Burger EH. Bone morphogenetic proteins in human bone regeneration. Eur J Endocrinol. 2000;142:9-21.

15. Polak SJ, Levengood L, Sheeny K, Wheeler MB, Maki AJ, Clark SG, Wagone Johnson AJ. Analysis of the roles of microporosity and BMP-2 on multiple measures of bone regeneration and healing in calcium phosphate scaffolds. Acta Biomater. 2010;2011:1760-71. 
16. Carreira AC, Lojudice FH, Halcsik E, Navarro RD, Sogayar MC, Granjeiro JM. Bone morphogenetic proteins: facts, challenges, and future perspectives. J Dent Res. 2014;93:335-45.

17. Neovius E, Lemberger M, Docherty Skogh AC, Hilborn J, Engstrand T. Alveolar bone healing accompanied by severe swelling in cleft children treated with bone morphogenetic protein-2 delivered by hydrogel. J Plast Reconstr Aesthet Surg. 2013;66:37-42.

18. Shields LBE, Raque GH, Glassman SD, Campbell M, Vitaz T, Harpring J, Shields CB. Adverse effects associated with high-dose recombinant human bone morphogenetic protein-2 use in anterior cervical spine fusion. Spine. 2006:31:542-7

19. Schiller J, Fuchs B, Arnhold J, Arnold K. Contribution of reactive oxygen species to cartilage degradation in rheumatic diseases: Molecular pathways, diagnosis and potential therapeutic strategies. Curr Med Chem. 2003;10: 2123-45.

20. Hyzy SL, Olivares-Navarrete R, Schwartz Z, Boyan BD. BMP2 induces osteoblast apoptosis in a maturation state and noggin-dependent manner. J Cell Biochem. 2012;113:3236-45.

21. Poynton AR, Lane JM. Safety profile for the clinical use of bone morphogenetic proteins in the spine. Spine. 2002;27:S40-8.

22. Schickle K, Zurlinden K, Bergmann C, Lindner M, Kirsten A, Laub M, et al. Synthesis of novel tricalcium phosphate-bioactive glass composite and functionalization with rhBMP-2. J Mater Sci Mater Med. 2011;22:763-71.

23. Lee W, Wiseman ME, Cho N, Glenn JS, Frank CW. The reliable targeting of specific drug release profiles by integrating arrays of different albuminencapsulated microsphere types. Biomaterials. 2009;30:6648-54.

24. Bernstein A, Suedkamp N, Mayr HO, Kissling S, Seidenstuecker M. Microporous B-Tricalcium Phosphate (TCP) - A delivery vehicle of growth factors and drugs. Key Eng Mater. 2013;587:93-6.

25. Seidenstuecker M, Mrestani Y, Neubert RHH, Bernstein A, Mayr HO. Release kinetics and antibacterial efficacy of microporous B-TCP coatings. J Nanomater. 2013;2013:8.

26. Straatmann A. Bestimmung physikalisch-chemischer Eigenschaften von Alginatlösungen und -gelen und von Lösungen Extrazellulärer Polymerer Substanzen von Pseudomonas aeruginosa SG81 mit der analytischen Ultrazentrifuge [Dissertation]. Duisburg: Universität Duisburg-Essen; 2003.

27. Seidenstuecker M, Kissling S, Mayr HO, Bernstein A. Vakuumbasiertes Beladungssystem für zylindrische mikroporöse ß-TCP Formkörper mit Hydrogelen. Bionanomaterials. 2014;2013:161.

28. Zurlinden K, Laub M, Dohle DS, Jenissen HP. Immobilization and controlled release of vascular (VEGF) and bone growth factors (BMP-2) on bone replacement materials. Biomed Tech. 2012;2012:989-91.

29. Kißling S, Seidenstücker M, Südkamp N, Mayr HO, Bernstein A. BMPFreisetzungsverhalten aus B-TCP Scaffolds in Kombination mit verschiedenen Hydrogelen als Carrier. Bionanomaterials. 2013;2013:51.

30. Woodruff MA, Rath SN, Susanto E, Haupt LM, Hutmacher DW, Nurcombe V, Cool SM. Sustained release and osteogenic potential of heparan sulfatedoped fibrin glue scaffolds within a rat cranial model. J Mol Histol. 2007;38: 425-33.

31. Sawyer AA, Song SJ, Susanto E, Chuan P, Lam CX, Woodruff MA, et al. The stimulation of healing within a rat calvarial defect by $\mathrm{mPCL}-\mathrm{TCP} / \mathrm{collagen}$ scaffolds loaded with rhBMP-2. Biomaterials. 2009;30:2479-88.

32. Hollinger JO, Schmitt JM, Buck DC, Shannon R, Joh SP, Zegzula HD, Wozney J. Recombinant human bone morphogenetic protein-2 and collagen for bone regeneration. J Biomed Mater Res. 1998;43:356-64.

33. Bodde EW, Boerman OC, Russel FG, Mikos AG, Spauwen PH, Jansen JA. The kinetic and biological activity of different loaded rhBMP-2 calcium phosphate cement implants in rats. J Bone Miner Res. 2008;87:780-91.

34. Li M, Liu X, Liu X, Ge B. Calcium phosphate cement with BMP-2-loaded gelatin microspheres enhances bone healing in osteoporosis. Clin Orthop Relat Res. 2010;468:1978-85.

35. Govender S, Csimma C, Genant HK, Valentin-Opran A, Amit Y, Arbel R. Recombinant human bone morphogenetic protein-2 for treatment of open tibial fractures: a prospective, controlled, randomized study of four hundred and fifty patients. J Bone Joint Surg. 2002;84:2123-34.

36. Kim HK, Oxendine I, Kamiya N. High-concentration of BMP2 reduces cell proliferation and increases apoptosis via DKK1 and SOST in human primary periosteal cells. Bone. 2013;54:141-50.
37. Patterson J, Siew R, Herring SW, Lin AS, Guldberg R, Stayton PS. Hyaluronic acid hydrogels with controlled degradation properties for oriented bone regeneration. Biomaterials. 2010;31:6772-81.

38. Rahman CV, Ben-David D, Dhillon A, Kuhn G, Gould TWA, Müller R, et al. Controlled release of BMP-2 from a sintered polymer scaffold enhances bone repair in a mouse calvarial defect model. J Tissue Eng Regen Med. 2014;8:59-66.

39. Hulsart-Billström G, Hu Q, Bergmann K, Jonsson KB, Aberg J, Tang R, et al. Calcium phosphates compounds in conjunction with hydrogel as carrier for BMP-2: a study on ectopic bone formation in rats. Acta Biomater. 2011; 3042-9.

40. Draenert FG, Nonnemacher AL, Kämmerer PW, Goldschmitt J, Wagner W. BMP2 and bFGF release and in vitro effect on human osteoblasts after adsorption to bone grafts and biomaterials. Clin Oral Implants Res. 2012; 2012:1-8.

41. Fromigué O, Marie PJ, Lomri A. Bone morphogenetic protein-2 and transforming growth factor-beta2 interact to modulate human bone marrow stromal cell proliferation and differentiation. J Cell Biochem. 1998; 68:411-26.

42. Kim SE, Song SH, Yun YP, Choi BJ, Kwon IK, Bae MS, et al. The effect of immobilization of heparin and bone morphogenic protein-2 (BMP-2) to titanium surfaces on inflammation and osteoblast function. Biomaterials. 2011;32:366-73.

43. Lee DW, Yun YP, Park K, Kim SE. Gentamicin and bone morphogenic protein-2 (BMP-2)-delivering heparinized-titanium implant with enhanced antibacterial activity and osteointegration. Bone. 2012;50:974-82.

44. Kisiel M, Klar AS, Ventura M, Buijs J, Mafina M, Cool SM, Hilborn J. Complexation and sequestration of BMP-2 from an ECM mimetic hyaluronan gel for improved bone formation. PLOS ONE. 2013;8:e78551.

45. Kisiel M, Ventura M, Oommen OP, George A, Walboomers XF, Hilborn J, Varghese OP. Critical assessment of rhBMP-2 mediated bone induction: An in vitro and in vivo evaluation. J Control Release. 2012;162:646-53.

\section{Submit your next manuscript to BioMed Central and we will help you at every step:}

- We accept pre-submission inquiries

- Our selector tool helps you to find the most relevant journal

- We provide round the clock customer support

- Convenient online submission

- Thorough peer review

- Inclusion in PubMed and all major indexing services

- Maximum visibility for your research

Submit your manuscript at www.biomedcentral.com/submit 